\title{
A Brief Review On: Extraction of Natural Dyes from Barks of Mangrove \& Walnut Tree and their Applications
}

\author{
Vivek Murani ${ }^{1}$, Kumar Joshi ${ }^{2}$, Dr. Kuldeep R. Sharma ${ }^{3}$, Mr. Archit Dave ${ }^{4}$ \\ ${ }^{1,2}$ M.Sc. Students, Faculty of Applied Science, Parul University, Ahmedabad, India \\ Email: vivekmurani28 [at]gmail.com, kumarjoshi66 [at]gmail.com \\ ${ }^{3}$ Head of Department, Faculty of Applied Science, Parul University, Ahmedabad, India \\ Email: kuldeep.sharma [at]paruluniversity.ac.in \\ ${ }^{4}$ Assistant Professor, Faculty of Applied Science, Parul University, Ahmedabad, India \\ Email: architdave87 [at]gmail.com
}

\begin{abstract}
Dyes derived from natural materials like plant leaves, roots, bark, insect secretions, and minerals were the sole dyes out there to humans for the coloring of textiles till the discovery of the primary artificial dye in 1856. Recently, there has been associate degree increasing interest within the use of natural dyes in textile applications. this can be a result of the meticulous environmental standards imposed by several countries in response to the harmful and allergies associated with artificial dyes. Recent analysis shows that they will even be used to dye some artificial fibers. except for their application in textiles, natural dyes also are utilized in the coloration of food, medicines, handicraft articles, and in animal skin process, and lots of the dye yielding plants are used as medicines in various traditional healthful therapies. The artificial dyes utilized in business produce variant problems like, environmental problems and color removal in effluent. Nowadays, the event of natural dyes is monumental, every day, the new natural dyes are made-up. in this paper, various natural dyes extracted from the bark of the trees, walnut tree, mangrove tree, and its application and examines their future prospects.
\end{abstract}

Keywords: Dyes, Bark, Walnut tree, Mangrove tree, Applications

\section{Introduction}

Since prehistoric time natural dyes is employed for coloring of food substrate, leather also as fibers like wool, silk and cotton. The employment of non-allergic, non-toxic and ecofriendly natural dyes on textiles became a matter of serious importance thanks to the multiplied environmental awareness in order to avoid some risky synthetic dyes. [1] Natural dyes are often obtained from numerous components of plants together with leaf, barks, the natural dyes were extracted from natural plants for alternate to synthetic. The elements of some trees like, ebony tree, Turkish red pine tree, mangrove tree, gum tree, nut tree, siriasis tree and etc., have the power to dye the textile materials. Mostly, the bark of the tree able to produce dye. [2]. For coloration of materials several chemicals are used in textile industry. However, environmental problems within the production and application of synthetic dyes once more revived client interest in natural dyes throughout the last decades of the 20th century but the entire share of natural dyes within the textile sector is around just one late to bound technical and property problems concerned within the production and application of those dyes liken on accessibility in ready-to use standard type, quality for machine use, and restricted and non-duplicatable shades. Also, overexploitation of natural resources to get dyes could lead to deforestation and threaten species. For these reasons, the worldwide Organic Textiles commonplace (GOTS) permits the utilization of safe artificial dyes and prohibits the utilization of natural dyes from species. Varied analysis efforts are undertaken everywhere the planet to handle the shortcomings of natural dyes in view of the tremendous environmental advantage they provide. [3] they're non-toxic non -allergic to skin non cancer, simply offered and renewable. Color fastness is that the resistance of a cloth to change any of its color characteristic square measure extent of transfer of its colorants to adjacent that materials connected typically lightweight fastness wash fastness and rub fastness square measure considered far textile fibers. [4] Recent renaissance in analysis and development on natural dye production and application is observed thanks to increasing quality of more natural life-style supported naturally property product [5].Natural flora/fauna is packed with incomparable colors fascinating and attracting individual toward a huge range of prospects [6].A large variety of plant and animal/insect sources are known for the extraction of color [7] and their diversified use in textile coloring [8-10], [7] and purposeful finishing [7,11,5], food coloration [7], cosmetics [12], dyesensitized solar cells [13], histologic staining, $\mathrm{pH}$ indicator [14] different and several other application disciplines [15].The natural dyes were extracted from the varieties of tree. every tree has its own color. the colors made from these trees are unique and can't be matched with different dyes and coloring ways. With this, here we tend to area unit describing the extraction of dye from the bark of some commercially accessible tree like, mangrove tree, walnut tree.

\section{Source of Natural Dyes}

Natural dye may be obtained kind totally different sources. Since precedent days natural dyes could have a large range of shades and may be obtained from numerous a part of plants together with roots bark leaves to flowers and fruit [17] These dyes will be classified as following:

1) Natural dyes obtained from plants - Berry, flower, bark, leaf, seed etc. (e.g. catechu, Indigofera, myrobalan, pomegranate).

\section{Volume 9 Issue 11, November 2020


2) Natural dyes obtained from animal - shellfish, murex snail, cuttle and shellfish.

3) Natural dyes obtained from mineral - Clay, ochre and mineral. [18]

\subsection{Plants Dyes}

Numerous components of the many plants are found probably made in natural dye; components like root, bark, stem, seeds, and fruit may be wont to extract color. Some plants might possess over one color depending upon from that a part of the plant they're extracted $[7,20]$.

\subsection{Mineral Dyes}

These colorants are derived from the natural mineral sources. Mineral colors are created from refined natural organic compounds. a number of the vital mineral colorant are chrome yellow, iron buff, Nanking yellow, Prussian blue, and manganese brown. However, these are created in place creating handling of textile stiffer. [21]

\subsection{Animals Dyes}

Animals also are made supply of natural dyes. Dyes commonly are being extracted from the dried body of the insects; common examples are animal product, cochineal and chemical structures, botanic names moreover as $\mathrm{C} \mathrm{I}$ specification of a couple of standard natural dyes [8-10, 22, 23].

\section{Extraction of Natural Dyes}

\subsection{From the Bark of the Mangrove Tree [16]:}

Natural dyes are extracted from barks of mangrove tree (Rhizophora simple Blume) (Bandaranayake, 1998). mangrove barks area unit off from the timber as a result of to reduction of ash content in charcoal products and therefore the barks are extremely made in phenol content [49].phenol provides the natural color, the wealthy reddish brown to the tree and therefore the same color is extracted as dye [24].The dried bark was crushed in to powder for extraction of dye For extraction, Soxhlet equipment is employed [50].Water is used as solvent for extraction purpose. The extracted dye was applied on textile materials victimization AN exhaustion coloring method [49]. Mordants are used to improve the coloring method. Many mordants are used for this purpose like metallic element potassium sulfate, ferrous sulfate, copper sulfate and stannous chloride [46]. The colored textile material has naturally reddish brown in shade while not mordant as a result of [47] barks are wealthy in phenol. Completely different completely different $\}$ mordants produces different shades from pale to dark reddish brown. The mordants, metallic element potassium sulfate and copper sulfate area unit want to dye the silk materials [48]. the fabric to liquor quantitative relation 1:10 was adopted to dye the silk materials. The coloring was applied for one hour at boiling temperature. Natalya Puritanizing et al., want to dye the silk with four completely different concentration of mangrove tree extracts at four completely different coloring time, temperature and $\mathrm{pH}$ scale level. From his experiment, it's determined that there is increase in temperature the color strength is additionally increasing, that's the temperature is directly proportional to the color. [48]

\subsection{From the Bark of the Walnut Tree}

Juglans regia $\mathrm{L}$ is that the biology name of walnut tree belongs to Juglandaceae family. The walnut tree is effective tree as a result of the complete elements of the tree is helpful [27]. The walnut is that the most useful fruit and the shell is the material. The shell is tested and it's the potential coloring substrate for various textile materials [28]. the primary compound gift within the walnut tree is Juglone, (5hydroxy-1, 4-naphthoquinone) within the bark of the walnut tree and produces the brown color [29]. The collected bark of walnut is dried in shadow. The dried bark is crushed into powder using the grinder. The powder is sieved to get rid of the coarse particles [30]. The solution was wont to extract the dye from the bark of the walnut. The specified concentration of bark powder was soaked with the specified M: L quantitative relation. Then the temperature of Answer\} is increased to the cooking purpose (91oC-93oC) and maintained at that temperature for an hour. Then the answer is cooled to temperature and filtered using the paper. The residue was treated once more to extract the most color from the powder. The extracted resolution was wont to coloring the textile materials [31]. Ali khan et al., used to dye the wool fiber with dye extracted from the bark of the walnut tree. The coloring of wool was administrated at the cooking purpose for half-hour at the side of the natural dye and mordant [32]. Mordant is employed to analyses the effectiveness of the fastness properties of the natural colouring. $100 \mathrm{pc}$ metal aluminum salt and 5-hitter alum is employed as mordant. And post-mordanting method [33]. The dyed wool cloth is soaped with $5 \mathrm{~g} / \mathrm{l}$ of Epee soap resolution to get rid of the unfixed natural dyes. When the soaping, the material is dried in temperature. The unreal yarn and also the control samples were tested for color fastness like light-weight, rub and wash fastness with Indian ISO commonplace [34]. The samples exhibit sensible fastness properties in pre-mordanting with $100 \%$ metal aluminum salt and five-hitter alum [35]. The samples unreal while not mordant exhibits sensible light fastness [34].

\section{Applications}

\subsection{Natural Dyes for Food Coloration: [ 21,25 ]}

The use of natural pigments for coloring is receiving growing interest from each food makers also as consumers and there has been abundant interest within the development of latest natural colorants to be used in food business continued the replacement of artificial food dyes, as a result of the natural products area unit related to quality and health promotion whereas artificial pigments area unit critically assessed by consumers [36, 37]. The natural dye annatto typically being recognized as Bixa Orellana. It's a yelloworange dye obtained from the seeds of this plant. It has high biodegradability, low toxicity, and compatibility with the setting. Carotenoids, apocarotenoids, terpenes, terpenoids, sterols, and aliphatic compounds area unit main compounds found in all components of this plant and area unit according to exhibit a good vary of medical specialty activities. Annatto is employed in solar cells, leather, food, textile and

\section{Volume 9 Issue 11, November 2020}




\section{International Journal of Science and Research (IJSR) \\ SJIF (2019): 7.583}

other industries. [38] Natural dye may be used for wool dying from a currently a day some new sources additionally used for pure wool dying. Hollyhock, cotton rose, Caryatid, Teledus, Rambutan, and curcuma these plants area unit used for Animal proteins, like wool dye best in acidic conditions and are weakened by alkaline. Sources of natural dyes that are used, primarily offer color to wool usually in dye bath. [39] Natural dye obtained from plants like Black carrot, Hibiscus, DeLois, Plumeria, Combretum, Ixora, and Bischof has been used for dying silk cloth. [40]

\subsection{Insect Repellent Finishing: [21]}

Insect damage on textile products like carpets, garments, upholstered furniture, blankets, and valuable heirlooms may be a major problem faced throughout storage and ends up in significant economic losses, particularly Even a little quantity of fiber devoured from a valuable suit or a carpet will ruin its functional and/or aesthetic properties. Insect repellents that discourage insect damage in textile business are in nice demand. [41] studied damage to wool materials dyed with ten totally different natural dyestuffs by the larvae of various carpet bug, Anthrenusverbasci. Eight among the ten natural dyestuffs were found effective against Verbascum and strength of their repellent impact in feeding preference check was within the order of dye, gallnut, catechu, red cabbage, Circular cocoon extract cochineal, indigo, amur cork tree extract. The anthraquinone dyes, like cochineal and madder, were found to be very effective in protective wool cloth against black carpet beetles. Madder resulted within the lowest weight loss and therefore the best impact of insect deterrence against black carpet beetles.

\subsection{Natural Dyes in Dye-sensitized Solar Cell : [21,25]}

Solar energy has emerged in concert of the promising renewable energy sources for eco-friendly and efficient conversion of solar energy to electricity, due to the utilization of cheap materials, easy fabrication method and low environmental impact, particularly those allergic by natural dyes [42].In photo chemical science water rending metal dioxide-based semiconductors are used. For promote the potency of photo chemical science reaction natural dye sensitizers are used because of quick electron injection and slow backward reactions are exhibited by dye sensitizers. A protecting layer like semiconducting compound layer is needed for natural dye sensitizer as a result of its unstable in resolution. [43] Natural dye is employed as photosensitizer in dye allergic solar cells in conjunction with $\mathrm{TiO} 2$ nano particles extracted from Chemigraphic colorecta (Red flame) with nominal chemical procedure and is employed Anthocyanin and beta-carotene is present during this dye and it's established by UV-Visible absorption spectrographic analysis and micro-Raman qualitative analysis studies. The electrical phenomenon property of chemigraphic colorecta issue to the presence of high concentration of anthocyanin. [44]. Anthocyanin and pigment is natural sensitizers in dye allergic solar cells (DSCs) that are UV- Vis absorption activity showed that the mixture of 2 dyes enabled associate increased and wider absorption within the wavelength vary of chemically adsorbate onto the $\mathrm{TiO} 2$ film, whereas it's physical adsorption for pigment. The optimized ratio of the 2 dyes within the mixture was found to be $\sim 2: 5$, causing each comfortable charge transfer actuation and nominal energy loss.

\section{Conclusion}

Natural dyes, typically supposed to be low-cost, non-toxic, worthwhile, and property resource with least environmental impact, have attracted the eye of the scientific community to use them during a type of traditional and new discovered application disciplines. The natural dye extracted from the bark of the mangrove tree, walnut tree, A produces the distinctive color, that can't be matched with regular artificial coloring ways. Mostly, the liquid extraction methodology is followed for extraction of natural dye from the bark of the tree. This review is plan to highlight the undesirable impact of artificial dye on the surroundings and human's health. the information generated from these studies might device the idea for the economic viability of natural dye production in industrial scale for property utilization of bioresources.

\section{References}

[1] K. Agarwal, Application of natural dyes on textiles, Indian Journal of Fibre \& Textile Research, 34, 2009, 384-399,

[2] Deo, H. T. and Desai, B. K. (1999) 'Dyeing of cotton and jute with tea as a natural dye', Journal of the Society of Dyers and Colorists, 115(7-8), pp. 224-227. doi: 10.1111/j.1478-4408. 1999.tb00360. $\mathrm{x}$.

[3] (Sujata Saxena, A. S. M. Raja)

[4] Kulkarni. S.S, Gokhale. A.V, Bodake.U.M and Pathade.G.R, 2011 Cotton dyeing with Natural Dye Extracted from Pomegranate, Journal of Environmental Research and Technology, Vol. 1(2): 135-139.

[5] Grifoni, D, Bacci, L, Zipoli, G, Carreras, G, Baronti, S, Sabatini, F, Laboratory and Outdoor, Assessment of UV Protection Offered by Flax and Hemp Fabrics Dyed with Natural Dyes. Photochem, Photobiol, 85, 313-320, 2009.

[6] Dawson, TL, Biosynthesis and synthesis of natural colors. Color Technol, 125, 61-73, 2009.

[7] Yusuf, M, Shabbir, M, Mohammad, F, Natural colorants: Historical, Processing and Sustainable Prospects. Nat. Prod. Bioprospect, 7(1), 123-145, 2017.

[8] Adeel, S, Ali, S, Zsila, F, Dyeing of cotton fabric using pomegranate (Punica granatum) aqueous extract. Asian J. Chem, 21, 3493-3496, 2009.

[9] Adeel, S, Bhatti, IA, Kausar, A, Osman, E, Influence of UV radiations on the extraction and dyeing of cotton fabric with Curcuma longa $\mathrm{L}$. Indian J. Fibre Text Res, 37, 87-90, 2012.

[10] Yusuf, M, Shahid, M, Khan, MI, Khan, MA, Mohammad, F, Dyeing studies with henna and madder: A research on effect of tin (II) chloride mordant. J. Saudi Chem. Soc. 19, 64-72, 2015.

[11] Mansour, R, Haouas, N, Ben Kahla-Nakbi, A, Hammami, S, Mighri, Z, Mhenni, F, Babba, H, The effect of Vitisvinifera L. leaves extracts on Leishmania infantum. Iranian J. Pharmaceut Res, 12, 349-355, 2013.

\section{Volume 9 Issue 11, November 2020




\section{International Journal of Science and Research (IJSR)

[12] Dweck, AC, Natural ingredients for colouring and styling. Int. J. Cosmetic Sci, 24, 287-302, 2002.

[13] Hao, S, Wu, J, Huang, Y, Lin, J, Natural dyes as photosensitizers for dye-sensitized solar cell. Sol. Energy, 80(2), 209-214, 2006.

[14] Mishra, PK, Singh, P, Gupta, KK, Tiwari, H, Srivastava, P, Extraction of natural dye from Dahlia variabilis using ultrasound. Indian J. Fibre Text. Res, 37(1), 83-86, 2012

[15] Shahid, M, Mohammad, F, Recent advancements in natural dye applications: a review. J. Clean Prod, 53, 310-331, 2013.

[16] M Gobalakrishnan, R Ragavendran, E Santhosh, R Tamilvanan, A Review on the Extraction Of Natural Dye from The Tree, International Journal of Creative Research Thoughts, 2020, 4, 1486-1490

[17] Saravanan P, Chandramohan G, Mariajancyrani J, Shanmugasundaram P, Extraction and application of EcoFriendly Natural dye obtained from Leaves of Acalypha indica Linn on Cotton Fabric, International research journal of environment science. Vol 2 (12), 1 - 5, December (2013).

[18] Singh R. and Srivastava S, Exploration of Flower Based Natural Dyes - A Review Received 4th April 2015, revised 11thMay 2015, accepted 23rdMay 2015.

[19] Sinha, K, Saha, P.D, Datta, S, Response surface optimization and artificial neural networmodeling of microwave assisted natural dye extraction from pomegranate rind. Ind. Crops Prod, 37(1), 408-414, 2012.

[20] Rym Mansour, Natural Dyes And Pigments: Extraction and Applications, Handbook of Renewable Materials for Coloration and Finishing, 2018, 9, (75-102). DOI: 10.1002/9781119407850.ch5.

[21] Kharbade, B.V, Agrawal, O.P, Analysis of natural dyes in Indian historic textiles. JSTOR Studies Conserv, 33, 1-8, 1988.

[22]Zhang, X, Laursen, R.A, Development of mild extraction methods for the analysis of natural dyes in textiles of historical interest using LC-diode array detector-MS. Analytical Chem, 77(7), 2022-2025, 2005.

[23] Chapman V. J (1970) 'Mangrove phytosociology', Tropical Ecology, 1, pp. 1-19.

[24] J M CHEESEMAN and C E LOVELOCK (2004) 'Photosynthetic characteristics of dwarf and fringe Rhizophora mangle L. in a Belizean mangrove', Plant, Cell and Environment, 27, pp. 769-780.

[25] Mongkholrattanasit, R. et al. (2016) 'Dyeing, fastness and uv protection properties of cotton fabric dyed with mangrove bark extract', Cellulose Chemistry and Technology, 50(1), pp. 163-171.

[26] Doty, K, Haar, S. and Kim, J. (2016) 'Black walnut, Osage orange and eastern redcedar sawmill waste as natural dyes: effect of aluminum mordant on color parameters', Fashion and Textiles. Springer Singapore, 3(1). doi: 10.1186/s40691-016-0074-9.

[27] Tutak, M. and Benlí, H. (2011) 'Colour and fastness of fabrics dyed with walnut (Juglans regia L.) base natural dyes.', Asian Journal of Chemistry, 23(2), pp. 566-568.
[28] Wei, Q, Ma, X. and Dong, J. (2010) 'Preparation, chemical constituents and antimicrobial activity of pyroligneous acids from walnut tree branches', Journal of Analytical and Applied Pyrolysis, 87(1), pp. 24-28. doi: 10.1016/j.jaap.2009.09.006.

[29] Gobalakrishnan, M. and Saravanan, D. (2017) 'Antimicrobial Activity of Coleus Ambonicus Herbal Finish on Cotton Fabric', Fibres and Textiles in Eastern Europe, 25(4(124)), pp. 106109. doi: 10.5604/01.3001.0010.2854.

[30] Doğan-Sağlamtimur, N. et al. (2017) 'Production of dye from green and brown walnut shells for leather coloration', Periodicals of Engineering and Natural Sciences, 5(2), pp. 224-230. doi:

[31] 10.21533/pen. v5i2.135.

[32] Ali Khan, M, Shahid-Ul-Islam and Mohammad, F. (2016) 'Extraction of Natural Dye from Walnut Bark and its Dyeing Properties on Wool Yarn', Journal of Natural Fibers, 13(4), pp. 458-469. doi: 10.1080/15440478.2015.1055033.

[33] Gokhale, S. et al. (2004) 'Natural dye yielding plants', Indian Journal of Natural Products and Resources (IJNPR), 3(4), pp. 228- 234.

[34] Sharma, A. and Grover, E. (2011) 'Colour fastness of walnut dye on cotton', Indian Journal of Natural Products and Resources, 2(2), pp. 164-169

[35]Khalid, B. et al. (2010) 'Study of colour measurements of leather dyed with walnut bark natural dye', Pakistan Journal of Scientific and Industrial Research, 53(5), pp. 252-257.

[36] Dawson, T.L, It must be green: meeting society's environmental concerns. Color Technol, 124(2), 67-78, 2008.

[37]Downham, A, Collins, P, Colouring our foods in the last and next millennium. Int. J. Food, Sci. Technol, 35(1), 5-22, 2000.

[38] Shahid-ul-Islam, Luqman J. Rather, Faqeer Mohammad, Phytochemistry, biological activities and potential of annatto in natural colorant production for industrial applications - A review. Journal of Advanced Research (2016)7, 499-514

[39]D. Shukla, P.S. Vankar, Natural Dyes for Textiles, Sources, Chemistry and Applications, A volume in Woodhead Publishing Series in Textiles 2017, Pages 167-190

[40]D. Shukla, P.S. Vankar, Natural Dyes for Textiles, Sources, Chemistry and Applications, A volume in Woodhead Publishing Series in Textiles 2017, Pages 141-166.

[41] Kato, H, Hata, T, Tsukada, M, Potentialities of natural dyestuffs as antifeedants against varied carpet beetle, Anthrenus verbasci. J. Japan Agric. Res. Quart, 38(4), 241-251, 2004.

[42] Narayan, M.R, Dye sensitized solar cells based on natural photosensitizers. Renew. Sust. Energy Rev, 16(1), 208-215, 2012.

[43] Siti Nur HidayahJaafar, Lorna JefferyMinggu, KhuzaimahArifin, Mohammad B.Kassim, Wan Ramli DaudWan, Natural dyes as TIO2 sensitizers with membranes for photoelectrochemical water splitting: An overview, Renewable and Sustainable Energy Reviews Volume 78, October 2017, Pages 698-709 
[44] V.G.Nandakumara..S.Suresha..C.O.Sreekalab..S.K. Sudheera. V.P.Mahadevan Pillaia, Hemigraphis colorata as a natural dye for solar energy conversion, Volume 4, Issue 2, Part C, 2017, Pages 4358-4365.

[45] Shivani Verma and Gunjan Gupta, Natural dyes and its applications: A brief review, International Journal of Research and Analytical Reviews, [VOLUME 4 I ISSUE 4 I OCT. - DEC. 2017], Page no.57-60.

[46] Gobalakrishnan, M. and Saravanan, D. (2017) 'Antimicrobial Activity of Coleus Ambonicus Herbal Finish on Cotton Fabric', Fibres and Textiles in Eastern Europe, 25(4(124)), pp. 106109. doi: 10.5604/01.3001.0010.2854.

[47] Norman C Duke and James A. Allen (2005) 'Species Profiles for Pacific Island Agroforestry (Atlantic East Pacific red mangrove)', Species Profiles for Pacific Island Agroforestry, 1(April), pp. 1-19.

[48] Punrattanasin, N. et al. (2013) 'Silk fabric dyeing with natural dye from mangrove bark (Rhizophora piculata Blume) extract', Industrial Crops and Products. Elsevier B.V, 49, pp. 122-129. doi: 10.1016/j.indcrop.2013.04.041.

[49] Nichol, C. J. et al. (2006) 'Assessing photosynthetic efficiency in an experimental mangrove canopy using remote sensing and chlorophyll fluorescence', Trees - Structure and Function, 20(1), pp. 9-15. doi: 10.1007/s00468-005-0005-7.

[50] Gobalakrishnan, M. and Saravanan, D. (2017) 'Antimicrobial Activity of Coleus Ambonicus Herbal Finish on Cotton Fabric', Fibres and Textiles in Eastern Europe, 25(4(124)), pp. 106109. doi: 10.5604/01.3001.0010.2854. 